\title{
PERBEDAAN KUALITAS TIDUR IBU HAMIL TRIMESTER III SEBELUM DAN SETELAH MELAKUKAN SENAM HAMIL DI DESA KARANG ANYAR KECAMATAN LANGSA BARO KOTA LANGSA
}

\author{
Fitria Yunanda ${ }^{1}$, Sarma Lumban Raja ${ }^{2}$, Ivansri Marsaulina Panjaitan ${ }^{3}$ \\ 1,2,3 Institut Kesehatan Helvetia, Medan \\ Email: fitriyunanda29@gmail.com,
}

\begin{abstract}
Abstrak
Salah satu keluhan yang dirasakan oleh wanita hamil di trimester tiga adalah gangguan tidur. Tidur yang tidak berkualitas baik dan tidak adekuat bisa menyebabkan gangguan fisiologis dan keseimbangan fisiologis. Upaya yang dapat dilakukan untuk mengatasi kesulitan tidur pada ibu hamil adalah dengan melakukan senam hamil. untuk mengetahui perbedaan dari kualitas tidur pada ibu hamil sebelum dan sesudah melakukan senam hamil. Penelitian yang dilakukan dengan metode experimenta dengan rancangan one group pretest-posttest design. Penelitian dilakukan di Desa Karang Anyar Kecamatan Langsa Baro Kota Langsa. Populasi penelitian ini adalah keseluruhan ibu hamil Trimester III sebanyak 18 orang dan seluruhnya dijadikan sampel penelitian. Analisis data menggunakan uji T berpasangan (Paired Sample T-test). Berdasarkan hasil penelitian menunjukkan hasil pretest dengan kualitas tidur buruk sebanyak 16 orang (88,9\%), dan hasil posttest dengan kualitas tidur baik sebanyak 12 orang $(66,7 \%)$. Perbedaan nilai mean antara kelompok pretest $(11,94)$ dan kelompok postest $(5,17)$, rata-rata nilai mean antara kedua kelompk (6,778). Hasil uji $t$-test menunjukkan hasil sig- $\alpha 0,000<0,05$. Terdapat perbedaan kualitas tidur sebelum dan sesudah diberikan perlakuan senam hamil pada ibu hamil trimester III Di Desa Karang Anyar Kecamatan Langsa Baro Kota Langsa. Disarankan kepada ibu hamil untuk meningkatkan pengetahuan dan pemahaman ibu hamil dalam mengatasi gangguan tidur dengan cara melakukan senam hamil di masa trimester III yang memiliki manfaat dan keuntungan yang baik bagi ibu hamil.
\end{abstract}

Kata Kunci : Ibu Hamil Trimester III, Kualitas Tidur, Senam Hamil

\begin{abstract}
One of the complaints felt by pregnant women in the third trimester is sleep disturbances. Sleep that is not of good quality and inadequate can cause physiological disturbances and physiological balance. Efforts that can be made to overcome sleep difficulties in pregnant women is to do pregnancy exercises. The purpose of this study was to determine the difference in the quality of sleep in pregnant women before and after doing pregnancy exercise. The research was conducted using an experimental method with a one group pretest-posttest design. The research was conducted in Karang Anyar Village, Langsa Baro District, Langsa City. The population of this study were 18 pregnant women in the third trimester and all of them were used as research samples. Data analysis used paired sample t-test. Based on the results of the study, the results of the pretest with poor sleep quality were 16 people (88.9\%), and the posttest results with good sleep quality were 12 people (66.7\%). The difference in the mean value between the pretest group (11.94) and the posttest group (5.17), the mean value between the two groups (6.778). The results of the t-test showed the results of sig- $\alpha 0.000<0.05$. There are differences in the quality of sleep before and after being given pregnancy exercise treatment for pregnant women in the third trimester in Karang Anyar Village, Langsa Baro District, Langsa City. It is recommended for pregnant women to increase knowledge and understanding of pregnant women in overcoming
\end{abstract}


sleep disorders by doing pregnancy exercises in the third trimester which has good benefits and advantages for pregnant women.

Keywords : Third Trimester Pregnant Women, Sleep Quality, Pregnancy Exercise

\section{Pendahuluan}

Kehamilan merupakan terjadinya proses pertemuan antara sperma dan ovum secara alami yang menghasilkan sel tunggal (zigot) (Janiwarty \& Pieter, 2013). Selama kehamilan seorang wanita hamil akan mengalami perubahan fisiologis. Rasa mual, muntah, meriang dan lemas akan dirasakan pada wanita yang hamil muda. Akan tetapi pada kehamilan trimester ketiga terjadinya pembesaran perut, perubahan anatomis dan perubahan hormonal hal tersebut menimbulkan berbagai keluhan pada wanita hamil (Venkata \& Venkateshiah, 2009).

Berbagai keluhan yang dirasakan oleh wanita hamil di trimester tiga yaitu napas terasa sesak, nyeri punggung bagian bawah, haemorrhoid, gangguan tidur, nyeri pada area pelvis, pusing, kram perut, sering buang air kecildan rasa tidak nyaman akibatkontraksi yang muncul tiba-tiba. Salah satu keluhan pada wanita hamil yang sering terjadi yaitu adanya gangguan dengan tidurnya, walaupun kehamilannya normal (Pieter \& Lubis, 2010).

Dari beberapa kondisi ibu hamil mengalami gangguan diantaranya yaitu pemenuhan kebutuhan kualitas tidur. Kebutuhan akan tidur yaitu kebutuhan yang paling mudah terpenuhi, tidur merupakan hal yang esensial bagi kesehatan. Istirahat dan tidur merupakan hal yang sama pentingnya harus di penuhi seperti kebutuhan yang lain. Tidur yang tidak berkualitas baik dan tidak adekuat bisa menyebabkan gangguan fisiologis dan keseimbangan fisiologis (Hidayat \& Uliyah, 2014).

Gangguan kualitas tidur pada ibu hamil sering dirasakan saat kehamilan trimester II dan III, hal tersebut terjadi karena perubahan adaptasi fisiologis dan psikologis, perubahan fisiologis yang dialami ibu hamil, dikarenakan bertambahnya usia kehamilan seperti pembesaran perut, perubahan anatomis dan perubahan hormonal (Pillitteri, 2020). Perubahan psikologis yang dialami ibu hamil lebih disebabkan karena kondisi cemas yang berlebihan, khawatir dan takut tanpa sebab, hingga akhirnya berujung pada kondisi depresi sehingga kualitas tidur pun terganggu. Kondisi stres inilah yang mengakibatkan otot tubuh menegang, terutama otot-otot yang berada di jalan lahir akan menjadi kaku dan keras sehingga mengganggu proses pembukaan jalan lahir. Selain itu ibu hamil yang mengalami gangguan tidur akan menjadi lebih lamban menghadapi rangsangan dan sulit berkonsentrasi ( Mirghaforvand, dkk, 2017).

Dampak dari gangguan kualitas tidur yang tidak teratur jika terjadi secara berkepanjangan selama kehamilan maka dikhawatirkan bayi yang akan dilahirkan memiliki berat badan lahir rendah (BBLR), perkembangan sarafnya tidak seimbang, lahir prematur dan melemahnya sistem kekebalan tubuh bayi. Selain itu juga gangguan tidur menimbulkan depresi dan stres yang berpengaruh pada janin yang dikandungnya. Stres ringan menyebabkan janin mengalami peningkatan denyut jantung, tetapi stres yang berat dan lama akan membuat janin menjadi menjadi lebih hiperaktif (Okun, dkk, 2011). 
Gangguan kualitas tidur pada ibu hamil juga dapat meningkatkan persalinan lama yang berujung pada persalinan secara operasi sesar (Wangel, dkk, 2011).

Manusia menggunakan sepertiga waktu dalam hidup untuk tidur. Data hasil polling tidur di Amerika oleh National Sleep Foundation didapat bahwa ternyata wanita lebih banyak mengalami gangguan tidur dibandingkan dengan laki-laki, yaitu 63\%:54\%. Penelitian National Sleep Foundation 97,3\% wanita hamil trimester tiga selalu terbangun dimalam hari. Rata-rata 3-11 kali setiap malam. Hasil survei menunjukkan 78\% wanita hamil di Amerika mengalami gangguan tidur dan hanya 1,9\% wanita yang tidak terbangun pada malam hari selama kehamilan trimester III.

Upaya-upaya yang dapat dilakukan untuk mengatasi kesulitan tidur pada ibu hamil antara lain antara lain dengan melakukan olahraga ringan yang aman untuk ibu hamil, hipnoterapi, memberikan pendidikan kesehatan bagaimana menjaga kualitas tidur dan latihan relaksasi (Marwiyah \& Sufi, 2018). Wanita hamil dianjurkan melakukan olahraga ringan seperti senam hamil agar ibu dan janin lebih sehat dan berkurangnya masalah-masalah yang timbul pada kehamilannnya. Dalam gerakan senam hamil terkandung efek relaksasi yang bermanfaat menstabilkan kecemasan dan mengurangi rasa takut dengan cara relaksasi fisik dan mental, serta mendapatkan informasi yang mempersiapkan mereka untuk mengalami apa yang akan terjadi selama persalinan dan kelahiran (Brayshaw, 2008).

Senam hamil merupakan salah satu pilihan dari terapi non farmakologi sehingga dapat berdampak pada peningkatan kualitas tidur. Pilihan menggunakan metode non farmakologi lebih tepat diberikan dalam penanganan gangguan tidur pada ibu hamil, karena penggunaan metode ini lebih tidak memiliki efek samping dibandingkan dengan metode farmakologi (Seyed, dkk, 2015).

Berdasarkan hasil studi pendahuluan pada ibu hamil yang berada di Desa Karang Anyar Kecamatan Langsa Baro Kota Langsa terhadap 10 orang ibu hamil trimester III atau 28 minggu, yang terdiri dari 4 ibu hamil primigravida dan 6 ibu hamil multigravida mengatakan sering merasakan gangguan dalam tidur, hal ini dikarenakan meningkatknya frekuensi buang air kecil selain itu juga sering mengalami kecemasan, rasa takut, khawatir akan kehaamilan dan proses persalinan, dan ibu hamil juga tidak mengetahui bahwa senam hamil dapat membantu ibu hamil dalam memperbaiki kualitas tidur yang buruk menjadi kualitas tidur yang baik.

Mengingat pentingnya manfaat senam hamil sebagai salah satu alternatif untuk mengurangi keluhan-keluhan ibu hamil yang mengakibatkan penurunan durasi waktu tidur, maka peneliti tertarik untuk melakukan penelitian tentang Pengaruh Senam Hamil Terhadap Kualitas Tidur Ibu Hamil di Desa Karang Anyar Kecamatan Langsa Baro Kota Langsa Tahun 2021. Adapun tujuan penelitian ini untuk mengetahui perbedaan dari kualitas tidur pada ibu hamil sebelum dan sesudah melakukan senam hamil.

\section{Metode Penelitian}


Penelitian yang dilakukan merupakan penelitian kuantitatif dengan metode experimental dengan rancangan one group pretest-posttest design. Penelitian ini dilakukan di Desa Karang Anyar Kecamatan Langsa Baro Kota Langsa dari bulan Juni s/d November 2021. Populasi dalam penelitian ini adalah keseluruhan ibu hamil Trimester III di Desa Karang Anyar Kecamatan Langsa Baro Kota Langsa dengan jumlah 18 orang. Teknik pengambilan sampel dalam penelitian ini ditetapkan dengan teknik total sampling yaitu seluruh populasi dijadikan sampel sebanyak 18 ibu hamil trimester III.

Penelitian ini dilakukan dengan cara melakukan penelitian di wilayah kerja Puskesmas Langsa Kota untuk mendapatkan informasi-informasi yang dibutuhkan untuk melanjutkan suatu penelitian. Pengamatan yang dilakukan dalam penelitian ini yaitu pengumpulan data dengan menggunakan kuesioner. Uji hipotesa menggunakan uji $\mathrm{T}$ berpasangan (Paired Sample T-test) karena menampilkan distribusi data tidak normal. Nilai signifikansi keputusan adalah jika nilai signifikansi $<0,005$ maka hipotesis diterima sedangkan jika nilai signifikansi >0,005 maka hipotesis ditolak.

\section{Hasil Dan Pembahasan}

Karakteristik Responden: Berdasarkan pada kategori umur 21-26 tahun sebanyak 9 orang $(50,0 \%)$, umur 27-32 tahun sebanyak 6 orang $(33,3 \%)$ dan umur $>32$ tahun sebanyak 3 orang (16,7\%). Pada kategori pendidikan rendah (SD-SMP) sebanyak 5 orang $(27,8 \%)$, pendidikan menengah (SMA/SMK) sebanyak 11 orang $(61,1 \%)$ dan pendidikan tinggi (D3-S1) sebanyak 2 orang $(11,1 \%)$. Pada kategori pekerjaan yang tidak bekerja sebanyak 17 orang $(94,4 \%)$ dan bekerja sebanyak 1 orang $(5,6 \%)$

Tabel 1. Distribusi Frekuensi Karakteristik Ibu Hamil Trimester III di Desa Karang Anyar Kecamatan Langsa Baro Kota Langsa Tahun 2021

\begin{tabular}{lcc}
\hline \multicolumn{1}{c}{ Karakteristik Responden } & \multicolumn{2}{c}{ Jumlah } \\
\cline { 2 - 3 } & F & \% \\
\hline Umur & 9 & 50,0 \\
21-26 tahun & 6 & 33,3 \\
$27-32$ tahun & 3 & 16,7 \\
>32 tahun & & \\
Pendidikan & 5 & 27,8 \\
Rendah & 11 & 61,1 \\
Menengah & 2 & 11,1 \\
Tinggi & & \\
Pekerjaan & 17 & 94,4 \\
Tidak Bekerja & 1 & 5,6 \\
Bekerja & $\mathbf{1 8}$ & $\mathbf{1 0 0 , 0}$ \\
\hline Total & \multicolumn{2}{c}{} \\
\hline
\end{tabular}

Analisis Univariat: Berdasarkan tabel 2. dapat diketahui bahwa ibu hamil trimester III sebelum diberikan perlakuan (pretest) infromasi senam hamil yang tidak melakukan senam hamil sebanyak 16 orang $(88,9 \%)$ dan yang melakukan sebanyak 2 orang $(11,1 \%)$, sedangkan hamil trimester III setelah diberikan perlakuan (posttest) informasi senam pada ibu hamil ditemukan seluruhnya melakukan senam hamil sebanyak 
18 orang $(100 \%)$. Berdasarkan kualitas tidur pada ibu hamil trimester III sebelum dilakukan perlakuan (pretest) diketahui pada kategori kualitas tidur buruk sebanyak 16 orang $(88,9 \%)$ dan kualitas tidur baik sebanyak 2 orang $(11,1 \%)$, sedangkan kualitas tidur pada ibu hamil trimester III setelah diberikan perlakukan (posttest) diketahui pada kategori kualitas tidur buruk sebanyak 6 orang $(33,3 \%)$ dan kualitas tidur baik sebanyak 12 orang $(66,7 \%)$.

Tabel 2. Distribusi Frekuensi Senam Hamil dan Kualitas Tidur pada Ibu Hamil Trimester III di Desa Karang Anyar Kecamatan Langsa Baro Kota Langsa Tahun 2021

\begin{tabular}{lcccc}
\hline \multirow{2}{*}{ Variabel } & \multicolumn{2}{c}{ Pretest } & \multicolumn{2}{c}{ Postest } \\
\cline { 2 - 5 } & F & \% & f & \% \\
\hline Senam Hamil & & & & \\
Tidak Melakukan & 16 & 88,9 & 0 & 0,0 \\
Melakukan & 2 & 11,1 & 18 & 100,0 \\
\hline Kualitas Tidur & 16 & 88,9 & 6 & 33,3 \\
Buruk & 2 & 11,1 & 12 & 66,7 \\
Baik & $\mathbf{1 8}$ & $\mathbf{1 0 0 , 0}$ & $\mathbf{1 8}$ & $\mathbf{1 0 0 , 0}$ \\
\hline Total & & &
\end{tabular}

Analisis Bivariat: Perbedaan nilai mean antara kelompok pretest $(11,94)$ dan kelompok postest $(5,17)$ dengan rata-rata nilai mean antara kedua kelompk $(6,778)$, yang dapat diartikan bahwa kualitas tidur ibu hamil trimester III semakin baik setelah diberikan perlakukan. Hasil uji $t$-test menunjukkan hasil sig- $\alpha 0,000<0,05$ diterima, yang artinya bahwa terdapat perbedaan terhadap kualitas tidur ibu hamil sebelum dan sudah senam hamil yang dilakukan ibu hamil trimester III.

Tabel 3. Uji T-Test pada Ibu Hamil Trimester III Sebelum (Pretest) dan Sesudah (Posttest) diberikan Perlakukan di Desa Karang Anyar Kecamatan Langsa Baro Kota Langsa Tahun 2021

\begin{tabular}{clccccc}
\hline No & & Kelompok & \multicolumn{2}{c}{ Mean } & \multicolumn{3}{c}{ Std. Deviation } & Sig \\
\hline 1 & Pretest & 11,94 & 6,778 & 4,439 & 2,734 & 0 \\
2 & Posttets & 5,17 & 6,000 \\
\hline
\end{tabular}

\section{Kualitas Tidur Ibu Hamil Trimester III Sebelum Senam Hamil}

Berdasarkan hasil penelitian didapatkan hasil bahwa ibu hamil trimester III sebelum diberikan perlakuan (pretest) infromasi senam hamil yang tidak melakukan senam hamil sebanyak 16 orang $(88,9 \%)$ dan yang melakukan sebanyak 2 orang $(11,1 \%)$, Berdasarkan kualitas tidur pada ibu hamil trimester III sebelum dilakukan perlakuan (pretest) diketahui pada kategori kualitas tidur buruk sebanyak 16 orang $(88,9 \%)$ dan kualitas tidur baik sebanyak 2 orang $(11,1 \%)$.

Masalah yang sering dialami ibu hamil pada trimester III adalah Gangguan tidur karena pengaruh hormon yang naik turun dan kekhawatiran berlebihan akan proses kelahiran biasanya ibu hamil menjadi sulit tidur atau insomnia. Keadaan ini tentu kurang baik untuk kesehatan ibu dan juga janin yang dalam tahap pematangan organ tubuhnya. 
Sulit tidur juga membuat emosi ibu hamil meningkat dan signifikan dan mudah marah sehingga hal ini kurang baik bagi janin dalam kandungannya (Widatiningsih \& Dewi, 2017). Faktor lain yang mempengaruhi tidur secara umum seperti pengaruh pencahayaan, perubahan temperatur, aktivitas dan rutinitas kerja yang akan mempengaruhi irama dan siklus tidur dan bangun sehari-hari. Pastinya setiap orang memiliki jam tidur biologis yang berbeda. Khususnya antara ibu hamil yang satu dengan yang lainnya juga memiliki jam tidur biologis yang berbeda-beda. Hal ini menjelaskan beberapa orang bisa tidur cepat sedangkan yang lainnya bisa tidur pada tengah malam bahkan subuh (Perry, 2010).

Hasil penelitian ini sejalan dengan penelitian yang dilakukan Dewi Taurisiawati Rahayu (2018) Dari hasil penelitian pada ibu hamil trimester III sebelum diberikan perlakuan senam hamil menunjukkan bahwa seluruh responden mengalami kualitas tidur sedang $(100 \%)$ dan tidak ada yang mengalami kualitas tidur baik. Gangguan atau kesulitan tidur yang dialami oleh sebagian besar ibu hamil, hal ini disebabkan sering berkemih dimalam hari dan kecemasan juga mulai muncul menjelang persalinan terutama pada primigravida (Rahayu \& Hastuti, 2018). Pada penelitian yang dilakukan oleh National Sleep Foundation (2007) dalam Husin (2014) menyatakan bahwa lebih dari 79\% ibu hamil mengalami ketidakaturan atau gangguan dalam tidurnya (Husin, 2014).

Menurut peneliti, dari hasil penelitian sebelum diilakukan senam hamil mayoritas ibu mengalami kualitas tidur yang kurang. Berdasarkan hasil kuesioner dari responden dapat diketahui bahwa dari 18 orang responden, didapatkan sebagian besar waktu tidur ibu hamil trimester III rata-rata jam 22.00 Wib ke atas, dan dengan waktu lebih dari 30 menit yang dibutuhkan saat mulai berbaring hingga tertidur. Durasi tidur yang dialami oleh sebagian besar ibu hamil trimester III adalah 5-6 jam setiap malamnya. Pada penelitian ini ditemukan gangguan tidur yang selalu muncul pada tiap responden berupa terbangun di malam hari untuk buang air kecil yang meningkat pada kehamilan, janin lebih aktif di malam hari, rasa lapar di malam hari dan posisi tidur kurang nyaman yang mengakibatkan sering terbangun setiap malamnya. Selain hal tersebut faktor cuaca atau suhu udara juga dapat mempengaruhi, dimana suhu udara yang panas dapat menyebabkan sering terbangun malam. Sehingga ibu hamil trimester III sering mengantunk ketika melakukan aktivitas di siang hari saat melakukan pekerjaan rumah.

\section{Kualitas Tidur Ibu Hamil Trimester III Sesudah Senam Hamil}

Berdasarkan hasil penelitian dapat diketahui bahwa ibu hamil trimester III setelah diberikan perlakuan (posttest) informasi senam hamil ditemukan seluruhnya melakukan senam hamil sebanyak 20 orang (100\%). Berdasarkan kualitas tidur pada ibu hamil trimester III setelah diberikan perlakukan (posttest) diketahui pada kategori kualitas tidur buruk sebanyak 6 orang $(33,3 \%)$ dan kualitas tidur baik sebanyak 12 orang $(66,7 \%)$.

Tidur yang cukup akan membuat ibu hamil lebih bugar dan sehat sehingga dapat beraktifitas dengan baik, janin yang dikandungnya pun akan tumbuh dengan sehat. Oleh karena itu, ibu hamil harus mengupayakan agar kecukupan tidurnya terpenuhi, yakni sekitar 7-8 jam perhari.Kebutuhan ini bisa terpenuhi dari tidur malam atau di kombinasikan dengan tidur siang.Jika tidur malam hanya bisa dilakukan 5-6 jam maka tidur siang perlu dilakukan 1-2 jam sehingga kebutuhan tidur tercukupi. Lebih baik lagi bila ibu hamil tidur hingga 9 jam perhari (Indivara, 2009). 
Hasil penelitian ini sejalan dengan penelitian yang dilakukan oleh Ni Nyoman D. Witari (2020), Hasil penelitian didapatkan bahwa ibu hamil mengalami kesulitan dan gangguan tidur akibat dari perubahan tubuh seperti, stress, pergerakan janin, uterus semakin membesar, sering buang air kecil, nyeri pinggang, sesak. Pada periode ini ibu hamil sering kali merasakan kecemasan menjelang persalinan yang berdampak pada kualitas tidur ibu hamil. Beberapa faktor yang menyebabkan ibu hamil sering mengalami gangguan tidur adalah seringnya berkemih pada malam hari, posisi tidur yang kurang nyaman, pembesaran uterus, sesak, nyeri dan gerakan janin.(Witari, 2020)

Menurut Brayshaw (2008) dalam penelitian Nila Marwiyah (2018) senam hamil merupakan salah satu pelayanan prenatal care yang dapat meningkatkan kenyamanan pada ibu hamil dan menurunkan kecemaasan pada ibu hamil, dengan melakukan senam hamil maka dapat memperlancar sirkulasi peredaran darah ketubuh dan janin, selain itu memperkuat dan membuat elastisitat otot-oto panggul, menjaga persendian, melatih otototot pernafasan dan juga meningkatkan kenyamanan pada ibu hamil (Marwiya \& Sufi, 2018).

Menurut peneliti, senam hamil merupakan terapi latihan gerak untuk mempersiapkan ibu hamil, secara fisik atau mental, agar persalinan cepat, aman, dan spontan. Dengan melakukan senam hamil secara teratur dan intensif, ibu hamil dapat menjaga kesehatan tubuh dan janin yang dikandung secara optimal. Hasil analisis penelitian bahwa dengan pemberian senam hamil dapat memberikan pengaruh yang positif terutama terhadap kualitas tidur ibu selama kehamilan. Hal ini dapat dirasakan oleh ibu hamil dimana setelah melakukan senam hamil dimana kualitas tidur ibu semakin membaik. Disamping itu senam hamil juga merupakan suatu latihan pada ibu hamil yang bertujuan untuk membantu otot dinding perut menjadi elastis pada saat pembearan uterus, memperbaiki keseimbangan fisik ibu hamil, membantu meningkatkan posisi ibu yang benar selam kehamilan dan juga melancarkan peredaran darah ibu sehingga meningkatkan kenyamanan ibu pada saat masa kehamilan.

\section{Perbedaan Kualitas Tidur Ibu Hamil Trimester III Sebelum dan Sesudah Melakukan Senam Hamil}

Berdasarkan hasil uji t-test diketahui bahwa terdapat perbedaan nilai mean antara kelompok pretest $(11,94)$ dan kelompok posttest $(5,17)$ dengan rata-rata nilai mean antara kedua kelompk $(6,778)$, yang dapat diartikan bahwa kualitas tidur ibu hamil trimester III semakin baik setelah diberikan perlakukan. Hasil uji $t$-test menunjukkan hasil sig- $\alpha 0,000$ $<0,05$ diterima, yang artinya bahwa terdapat perbedaan terhadap kualitas tidur ibu hamil sebelum dan sudah senam hamil yang dilakukan ibu hamil trimester III.

Senam hamil adalah program kebugaran yang diperuntukkan bagi ibu hamil dalam rangka mengencangkan sistem tubuh dan menyiapkan otot-otot yang diperlukan sebagai tambahan yang harus dialami selama kehamilan (Fauzia, 2012). Mengingat pentingnya manfaat senam hamil sebagai salah satu alternatif untuk mengurangi keluhankeluhan ibu hamil yang mengakibatkan penurunan kualitas tidur. Manfaat senam hamil adalah memperbaiki sirkulasi darah, mengurangi pembengkakan, memperbaiki keseimbangan otot, mengurangi risiko gangguan gastrointerstinal, termasuk sembelit, mengurangi kejang kaki atau kram, menguatkan otot perut, mempercepat proses 
penyembuhan setelah melahirkan dan meningkatkan kualitas tidur dan menguasai teknikteknik pernafasan dan dapat mengatur diri kepada ketenangan (Rukiyah \& Yulianti, 2019).

Hasil penelitian ini sejalan dengan penelitian yang dilakukan Qomnintatul Yumna (2020), hasil penelitian menunjukkan Adanya pengaruh senam hamil terhadap kualitas tidur ibu hamil ditandai dengan perbedaan yang bermakna antara pre-test dan post-test. Secara keseluruhan pada penelitian ini terjadi penurunan rata-rata skor kualitas tidur pada setiap komponennya (gangguan tidur, latensi tidur, durasi tidur, efisiensi tidur, kualitas tidur subjektif, konsumsi obat tidur, dan disfungsi aktivitas siang hari) setelah melakukan senam hamil yang berarti kualitas tidur semakin membaik (Yumna, 2020).

Hasil ini sejalan dengan penelitian yang dilakukan oleh Dewi T. Rahayu (2018). Hasil uji t-test diketahui Asymp.sig. (2-tailed) bernilai 0,000 atau $\mathrm{p}<0.01$ berarti terdapat perbedaan bermakna kualitas tidur pada pre-test dengan post-test ibu hamil trimester III Senam hamil memiliki beberapa manfaat diantaranya untuk menghilangkan keluhankeluhan selama hamil termasuk gangguan pola tidur. Ibu yang rajin mengikuti senam hamil diharapkan akan menjadi terlatih ketika melakukan sikap tubuh yang baik dan benar selama menjalani kehamilan akan membantu dalam mengurangi keluhan yang timbul selama kehamilan (Rahayu \& Hastuti, 2018).

Upaya yang dilakukan untuk mengatasi masalah pola tidur pada ibu hamil salah satunya adalah dengan melakukan latihan gerak tubuh, relaksasi, dan mengatur pola nafas ibu. Latihan gerak bisa dilakukan dengan menggunakan metode senam hamil. Latihan relaksasi pada senam hamil secara fsiologis akan menimbulkan efek relaks yang melibatkan syaraf parasimpatis dalam sistem syaraf pusat. Dimana salah satu fungsi syaraf parasimpatis ini adalah menurunkan produksi hormon adrenalin atau epinefrin (hormone stress) dan meningkatkan skresi hormone noradrenalin atau norepinefrin (hormone relaks) sehingga terjadi penurunan kecemasan serta ketegangan pada ibu hamil yang mengakibatkan ibu hamil menjadi lebih relaks dan tenang (Bobak, 2004).

Menurut peneliti dari hasil penelitian diketahui bahwa senam hamil memiliki dampak yang positif terhadap kualitas tidur ibu hamil pada trimester III. Hasil diketahui setelah dilakukan penelitian dan analisis data, diketahui bahwa setelah pemberian senam hamil selama 4 minggu dari hasil pengujian perbedaan nilai kualitas tidur sebelum dan setelah pemberian senam hamil menunjukkan perbedaan yang positif. Hal ini dapat diketahui bahwa dari sebelum dilakukan senam hamil mayoritas ibu memiliki kualitas tidur yang buruk dan setelah melakukan senam hamil dapat dikategorikan bahwa kualitas tidur ibu hamil trimester III semakin baik. Selain itu senam hamil akan membantu ibu dalam kondisi rileks akibat terbentuknya endorphin yang memberikan efek menenangkan. Dengan demikian ibu hamil mudah tidur dengan kualitas yang baik dengan ketentuan senam hamil dilakukan dengan teratur untuk mendapatkan hasil yang lebih optimal. Hal ini sesuai dengan teori (Brayshaw, 2008), untuk menangani masalah ganggun tidur pada ibu hamil, kita dapat memberikan beberapa metode untuk menstabilkan kualitas tidur yang baik, seperti menentukan posisi yang baik dan nyaman saat tidur, latihan relaksasi dasar, salah satunya dengan senam hamil. Senam hamil dapat berdampak positif untuk mengatasi gangguan tidur, namun penerapan senam hamil ini masih jarang digunakan, karena kurangnya kesadaran ibu hamil akan pentingnya senam hamil (Brayshaw, 2008). 


\section{Kesimpulan}

Berdasarkan hasil penelitian dan pembahasan maka dapat ditarik kesimpulan bahwa terdapat perbedaan kualitas tidur sebelum dan sesudah diberikan perlakuan senam hamil pada ibu hamil trimester III Di Desa Karang Anyar Kecamatan Langsa Baro Kota Langsa.

\section{Daftar Pustaka}

Bobak. (2004). Buku Ajar Keperawatan Maternitas. Edisi 4. Jakarta: EGC.

Brayshaw E. (2008). Senam Hamil dan Nifas (Pedoman Praktis Bidan). Jakarta: EGC.

Fauzia S. (2012). Buku Ajar Keperawatan Maternitas Kehamilan. Penerbit Kencana: Jakarta.

Hidayat AAA, Uliyah M. (2014). Pengantar Kebutuhan Dasar Manusia. Jakarta: Salemba Medika.

Husin F. (2014). Asuhan Kehamilan Berbasis Bukti. Jakarta: Sagung Seto.

Indivara N. (2009). The Mom's Secret: Rahasia Melahirkan Selamat \& Tidak Sakit. Yogyakarta: Pustaka Anggrek.

Janiwarty B, Pieter HZ. (2013). Pendidikan Psikologi Untuk Bidan Suatu Teori dan Terapannya. Kencana Prenada Media Group.

Marwiyah N, Sufi F. (2018). Pengaruh Senam Hamil Terhadap Kualitas Tidur Ibu Hamil Trimester II dan III di Kelurahan Margaluyu Wilayah Kerja Puskesmas Kasemen. Faletehan Heal J. 5(3):123-8.

Mirghaforvand M, Mohammad-Alizadeh-charandabi S, Zarei S, Effati-Daryani F, Sarand FS. (2017). The relationship between depression and sleep quality in iranian pregnant women. Int J Women's Heal Reprod Sci. 5(2):147-52.

National Sleep Foundation. (2007) Sleeping-thetrimester-3rd-trimester.

Okun ML, Schetter CD, Glynn LM. (2011). Poor sleep quality is associated with preterm birth. Sleep. 34(11):1493-8.

Perry P. (2010). Fundamental Of Nursing: Consep, Proses dan Practice. Edisi 7 Vol. 3. Jakarta: EGC.

Pieter HZ, Lubis NL. (2010) Pengantar Psikologi Untuk Kebidanan. Edisi Revi. Jakarta: EGC.

Pillitteri A. (2010). Maternal \& Child Health Nursing: Care of the Childbearing \& Childrearing Family. 6th edition.

Rahayu DT, Hastuti NH. (2018). Pengaruh Keteraturan Senam Hamil terhadap Kualitas Tidur pada Ibu Hamil Trimester III di Desa Gedangsewupare Kediri. J Kebidanan Midwiferia. 4(2):34-45.

Rukiyah AY, Yulianti L. (2019). Asuhan Kebidanan Kehamilan Berdasarkan Kurikulum Berbasis Kompetemsi.

Seyed Ahmadi Nejad FS, Golmakani N, Shakeri MT. (2015). Effect of progressive muscle relaxation on depression, anxiety, and stress of primigravid women. Evid based care. 5(1):67-76.

Venkata C, Venkateshiah SB. (2009). Sleep-disordered breathing during pregnancy. J Am Board Fam Med. 22(2):158-68.

Wangel A-M, Molin J, Östman M, Jernström H. (2011). Emergency cesarean sections can be predicted by markers for stress, worry and sleep disturbances in first-time 
mothers. Acta Obstet Gynecol Scand. 90(3):238-44.

Widatiningsih S, Dewi CHT. (2017). Praktik Terbaik Asuhan Kehamilan. In Yogyakarta: Trans Medika.

Witari NND. (2020). Pengaruh Intervensi Senam Hamil dalam Menurunkan Stres dan Meningkatkan Kualitas Tidur Ibu Hamil Trimester III: The Effect of Pregnancy Exercise Intervention in Reducing Stress and Improving Sleep Quality on Pregnant Women in Their Third Trimester. Bali Med J. 7(2):174-82.

Yumna Q. (2020). Pengaruh senam hamil terhadap kualitas tidur ibu hamil pada usia kehamilan 13 sampai 30 minggu di wilayah kerja Puskesmas Batu dan Junrejo. Universitas Islam Negeri Maulana Malik Ibrahim.aniwarty B, Pieter HZ. Pendidikan Psikologi Untuk Bidan Suatu Teori dan Terapannya. Kencana Prenada Media Group; 2013. 